\section{A New Band Deployment System: Do We Really Need Two Threads?}

Endoscopic variceal ligation (EVL) has an established role in the primary and secondary prophylaxis of esophageal variceal bleeding [1]. Various types of ligators are available. The Stiegmann-Goff ligator works on the principle of deploying the band by pulling a trip wire [2]. It has the disadvantage of requiring repeated introduction, thus needing placement of an overtube which has its own complications [2]. The multishooters have the advantage of needing only a single introduction for multiple band application, and the bands are deployed when threads are pulled. However, the two threads in the cylinder hamper the endoscopic view. In addition, the cotton thread is hydrophilic causing sticking of secretions over it, which also hampers the endoscopist during ligation; this is especially important during active bleeding. The two threads in the ligator cylinder also affect complete "red out".

We have endeavored to obviate these disadvantages by modifying the deployment system. Instead of using two threads for pulling the bands we employed a single thread (Figure 1). Single-thread ligator cylinders were used in 25 patients to deploy a total of 90 bands, after multiple in vitro practice attempts. The technique was successful in all patients. The single thread in the cylinder permitted a better endoscopic view. With the single thread lying to one side, we were able to achieve "red out" at every attempt.

The pull pressure required for deployment of bands by both methods was compared in "dry runs." It was found that the double-thread system required greater

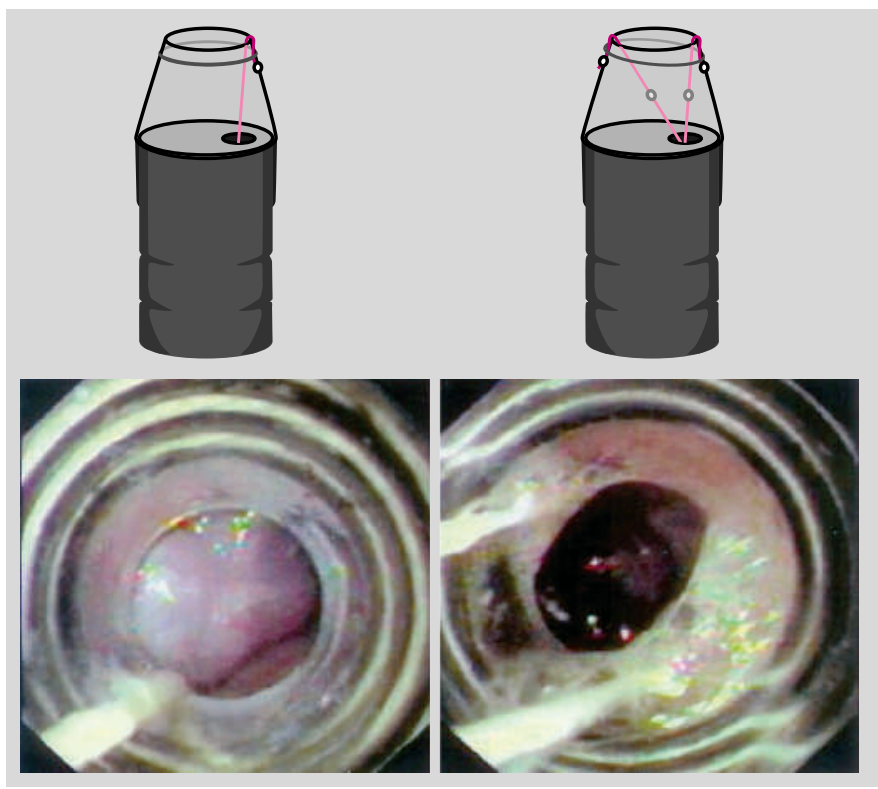

Figure 1 Diagrams and endoscopic photographs showing the singleand double-thread systems.

pressure, which may have a detrimental effect on the endoscope [3].

In conclusion, the technical advantages of the single-thread over the double-thread method are easier application, better view and suction, and a good "red out."

\section{S. Nijhawan, A. Joshi, A. Shende,}

\section{A. Mathur, R. R. Rai}

Department of Gastroenterology, SMS Hospital and Medical College, Jaipur, India.

\section{References}

${ }^{1}$ Sarin SK, Lamba GS, Kumar Met al. Comparison of endoscopic ligation and propranolol for the primary prevention of variceal bleeding. $N$ Engl J Med 1999; 340: 988 - 993

2 de Franchis R, Primignani M. Endoscopic treatments for portal hypertension. Semin Liver Dis 1999; 19: 439 455

${ }^{3}$ Govil A, Kumar N. Endoscope break dances while the bands play. Trop Gastroenterol 1995; 16: 64

\section{Corresponding Author}

\section{S. Nijhawan, M.D., D.M.}

Department of Gastroenterology,

SMS Hospital and Medical College

112, Panchsheel Enclave

Gokulbhai Bhatt Marg

Durgapura

Jaipur

302017 India

Fax: $\quad+91-141-2560994$

Fax: $\quad+39-49-343769$

E-mail: dr_nijhawan@yahoo.com 